\title{
Waterfowl Impoundments as Sources of Nitrogen Pollution
}

\author{
R. Scott Winton • Michelle Moorman • \\ Curtis J. Richardson
}

Received: 6 June 2016 / Accepted: 9 September 2016 / Published online: 29 September 2016

(C) Springer International Publishing Switzerland 2016

\begin{abstract}
Hydrologically controlled moist-soil impoundment wetlands provide critical habitat for high densities of migratory bird populations. Nutrients exported from heavily used impoundments by prescribed seasonal drawdown of surface water may contribute to the eutrophication of aquatic ecosystems. To investigate the relative importance of nutrient export from managed impoundment habitats, we conducted a field study at Mattamuskeet National Wildlife Refuge in North Carolina, USA, which contains 1545 ha of impoundments that drain into hypereutrophic Lake Mattamuskeet. We found that prescribed hydrologic drawdowns of an impoundment exported roughly the same amount of nitrogen $(\mathrm{N})$ as adjacent fertilized agricultural fields on a per-area basis and contributed approximately one fifth of total $\mathrm{N}$ load to Lake Mattamuskeet. The prescribed drawdown regime, designed to maximize waterfowl production in impoundments, may be exacerbating the degradation of habitat quality in the downstream lake as an unintended consequence. Few studies of wetland $\mathrm{N}$ dynamics have
\end{abstract}

Electronic supplementary material The online version of this article (doi:10.1007/s11270-016-3082-x) contains supplementary material, which is available to authorized users.

R. S. Winton $(\bowtie) \cdot$ C. J. Richardson

Duke University Wetland Center, Nicholas School of the Environment, Box 90333, Durham, NC 27708, USA

e-mail: scott.winton@gmail.com

M. Moorman

U.S. Fish and Wildlife Service, Mattamuskeet National Wildlife Refuge Office, Headquarters Rd, Fairfield, NC 27826, USA targeted impoundments managed to provide wildlife habitat, but a similar phenomenon may occur in some of the 36,000 ha of similarly managed moist-soil impoundments on National Wildlife Refuges in the southeastern USA, especially those hosting dense concentrations of waterfowl. We suggest an earlier seasonal drawdown could potentially mitigate impoundment $\mathrm{N}$ pollution and estimate it could reduce $\mathrm{N}$ export from our study impoundment by more than $70 \%$.

Keywords Wetlands - Wildlife management . Biogeochemistry $\cdot$ Denitrification

\section{Introduction}

The eutrophication of aquatic ecosystems has been a growing concern (Smith 2003). Blooms of phytoplankton in response to increased nutrient inputs trigger a progression of adverse impacts on other organisms in lakes and estuaries (Borum 1985; Cambridge and McComb 1984; Kemp et al. 1983, 2004; McGlathery 1995; Tomasko et al. 1996). Excess nutrients often lead ecosystems to a shift from a macrophyte- to a phytoplankton-dominated state (Orth and Moore 1983; Short and Wyllie-Echeverria 1996; Walker and McComb 1992), which is a particular concern for wildlife managers because aquatic plants create rich habitat and food for waterfowl, fish, and invertebrate populations (Heck et al. 1995; Lubbers et al. 1990).

Wetlands are hotspots for nitrogen $(\mathrm{N})$ cycling and removal via denitrification and are important sinks for 
excess sediment-bound phosphorus (P). However, the capacity for wetlands to provide bioremediation of nutrient pollution has been limited by historical losses of $50 \%$ of wetland areas in the USA (Dahl 2011). On North Carolina's low-lying Albemarle-Pamlico peninsula, historical wetland losses have been particularly dramatic because of ditching and drainage to reap the benefits of poorly drained, but exceptionally fertile cropland (Copeland et al. 1983; Hearns 1910). Despite a nation-wide hiatus (Dahl 2011), wetland losses caused by development in this region have continued in recent decades (Carpenter and Dubbs 2012).

Losses of natural wetlands have made constructed public and private impounded wetlands especially important for North American waterfowl populations (ducks, geese, and swans), which have recovered from historic lows of the 1930s (North American Waterfowl Management Plan Committee 2012). Overwintering waterfowl flocks are often concentrated in managed moist-soil impoundment habitats which provide a high density of preferred food items and attract a corresponding high density of waterfowl. Moist-soil management is often described as "an art," as optimal practices vary considerably based on biological, climatic, and physiogeographic context, but the key is managing hydrology to effectively support palatable wetland vegetation for waterfowl (Johnson and Montalbano 1989; Strader et al. 2005). Typically, this involves a spring drawdown in which impoundments are dewatered passively, by removing flash-board risers, and/or actively, by pumping.

Impoundment drawdown sends a pulse of water and nutrients downstream, the magnitude of which is based on water depth and nutrient concentrations. Since high bird densities are associated with elevated surface water nutrients (Gould and Fletcher 1978; Manny et al. 1994; Olson et al. 2005; Post et al. 1998), the potential exists for heavy nutrient loading from impoundments that attract large flocks of waterfowl. An investigation into the potential water-quality impacts of waterfowl at a refuge in New Mexico concluded that waterfowl impoundments have the potential to export both $\mathrm{N}$ and $\mathrm{P}$ based on observed increases in concentrations from inflow to outflow (Brandvold et al. 1976). The Brandvold et al. (1976) study, however, lacked nutrient budgets and has not been emulated in other regions. Thus, the export of nutrients from heavily used bird habitats to downstream lakes and estuaries has not been well explored.

Nutrient export from managed wetlands may be especially important in the context of Lake Mattamuskeet, which drains large areas of public and private impoundments and has suffered from recent declines in water clarity and submerged aquatic vegetation (SAV) associated with increased nutrient and suspended sediment content and phytoplankton blooms (Moorman et al., unpublished data; North Carolina Department of Health Environment and Natural Resources 2013; US Fish and Wildlife Service 2015). The loss of macrophyte coverage is a serious concern for Mattamuskeet National Wildlife Refuge, which was established in 1934 to maintain and promote wetland habitats for migratory bird populations, especially wintering waterfowl in and around the Lake. The Refuge attracts roughly 200,000 to 300,000 annually waterfowl and is of critical importance to Atlantic Flyway populations, many of which depend on the Lake's declining beds of SAV.

The purpose of this paper is to quantify nutrient loading to Lake Mattamuskeet by the surrounding managed impoundment wetlands and the large waterfowl population they host. Since surface P concentrations were relatively low, we mainly focus our analysis on the relative importance of $\mathrm{N}$ loading. We compare $\mathrm{N}$ sources in the watershed, i.e., agricultural runoff/ leaching, wet deposition, and direct transport by bird flocks (Post et al. 1998), to generate a preliminary $\mathrm{N}$ budget for Lake Mattamuskeet. We analyze and discuss the potential to mitigate impoundment $\mathrm{N}$ export through modification of hydrologic management prescriptions for increased denitrification and/or decreased mass loading.

\section{Methods}

\subsection{Site Description}

Lake Mattamuskeet, the centerpiece of Mattamuskeet National Wildlife Refuge, is a natural lake system located on the Albemarle-Pamlico Peninsula on the eastern coast of North Carolina (Fig. S1). Understanding and mitigating local water-quality problems is complicated because of the lake's large surface area $(\sim 16,500 \mathrm{ha})$, extensive shoreline $(\sim 120 \mathrm{~km})$, and shallow depth (average of $1 \mathrm{~m}$ ) which fluctuates on a daily, seasonal, and yearly basis as a result of climatic conditions. The lake also has a long history of hydrological alteration. In the mid-nineteenth century, the first canal from the lake to Pamlico Sound decreased the lake's depth from 3 to $1 \mathrm{~m}$. 
Three additional drainage canals have since decreased the lake's surface area from its original 48,000 ha to its current size (Forrest 1999; Waters et al. 2009, 2010). Between 1915 and 1932, the lake bottom was drained three times and farmed twice (Forrest 1999; Waters et al. 2010). The north-south-oriented North Carolina Highway 94 divides Lake Mattamuskeet into eastern and western regions, which have different nutrient regimes (Fig. S1; Waters et al. 2010).

Lake Mattamuskeet historically contained dense beds of SAV, but recent monitoring by the US Fish and Wildlife Service indicates that a decline in both SAV cover and water-quality conditions is now occurring lake wide (Moorman et al., unpublished data; US Fish and Wildlife Service 2015). Increasing trends in chlorophyll $a$, total $\mathrm{N}$ and total $\mathrm{P}$, and frequent exceedances of the North Carolina water-quality standard for chlorophyll $a$ have been detected on both sides of Lake Mattamuskeet (Moorman et al., unpublished data; US Fish and Wildlife Service 2015). Evidence from a recent flask nutrient addition experiment indicates that the lake phytoplankton growth is $\mathrm{N}$ limited (Davis et al. 2016), a result supported by other findings of N-limited shallow eutrophic lakes (Downing and Mccauley 1992; Healey and Hendzel 1980; Hecky and Guildford 1984). However, the high N/P ratio (44 by mass) of lake water indicates a potential for seasonal $\mathrm{P}$ limitation (Kolzau et al. 2014). Nevertheless, the prevailing wisdom is that harmful algal blooms at Lake Mattamuskeet may be caused or exacerbated by allochthonous N inputs from the watershed (Davis et al. 2016; US Fish and Wildlife Service 2015).

Our study site, Marsh Impoundment 10 North (MI10N; 35 $32^{\prime} 08 \mathrm{~N}, 76^{\circ} 04^{\prime} 24 \mathrm{~W}$ ), lies at the east end of the refuge, is closed to hunting, and has restricted public access (Fig. S1). Dominant plant species in MI10N include Phragmites australis, Eleocharis quadrangulata, Eleocharis parvula, Panicum dichotomiflorum, Bacopa monnieri, Echinochloa walteri, Centella spp., and Alternanthera philoxeroides. MI10N soil is mapped as Weeksville loam (95\%) and Engelhard loamy very fine sand (5 \%) (Soil Survey Staff 2015).

A network of canals, water-control structures, and pumps allow Mattamuskeet National Wildlife Refuge staff to control impoundment water levels, which they do, following an Annual Marsh/Water Management Plan prepared by the US Fish and Wildlife North Carolina Migratory Bird Field Office to meet population and habitat objectives for migratory waterfowl and shorebirds (Stanton, personal communication). The 2014 protocol recommended two phases of water level management: (1) water level at MI10N should be drawn down to top of outlet perimeter ditch, a level at which much of impoundment surface soil is exposed, by 1 June; (2) re-flooding should start 1 September with a goal of $30 \mathrm{~cm}$ of standing water by 1 December. With sufficient rainfall, re-flooding can be accomplished passively by placing stop-logs in flash-board risers, but often supplemental pumping is needed to meet target water levels. Starting 12 June 2013 pumps were run for approximately 8 days to drawdown $16 \mathrm{~cm}$ of standing water from MI10N (Fig. 1). Starting 9 May 2014, pumps were run for approximately 17 days to drawdown $34 \mathrm{~cm}$ of standing water (Fig. 1). It was not clear how much water was pumped (if any) to re-flood impoundments during the study.

\subsection{Watershed Land Cover Estimation}

Prior to European settlement, much of the land surrounding Lake Mattamuskeet consisted of pocosin peatlands (Richardson 1983), but in the past century, vast areas of pocosins have been ditched and drained to facilitate agriculture and silviculture (Copeland et al. 1983). As a result, the hydrology on the Albemarle Peninsula is a complicated maze of canals, drainage ditches, and pumps. We estimated land cover by clipping the 2006 National Land Cover Database with a watershed boundary created by the US Fish and Wildlife Service (Fry et al. 2011), a modification of the existing boundary in the National Hydrography dataset based on local landowner reports of drainage patterns. We estimated winter impoundment cover by clipping an impoundment shapefile created in 2012 by the North Carolina Wildlife Resources Commission with the watershed boundary.

\subsection{Water and Soil Analyses}

We collected four replicate surface water samples and 16 pore water samples monthly in spring of 2013 and 2014 from randomly placed research plots in the impoundment. Following drawdowns, puddles and large pools of standing water remained in the impoundment, allowing us to collect surface water samples even during periods of relatively low water. Site visits were timed to coincide with light winds (high winds interfere with trace gas sampling and cause sediment suspension) 
Fig. 1 Water level relative to impoundment surface elevation and surface water temperature at Marsh Impoundment 10 North at Mattamuskeet National Wildlife Refuge during the months surrounding spring drawdown in 2013 and 2014. Gray shading highlights period of prescribed drawdown by Refuge management

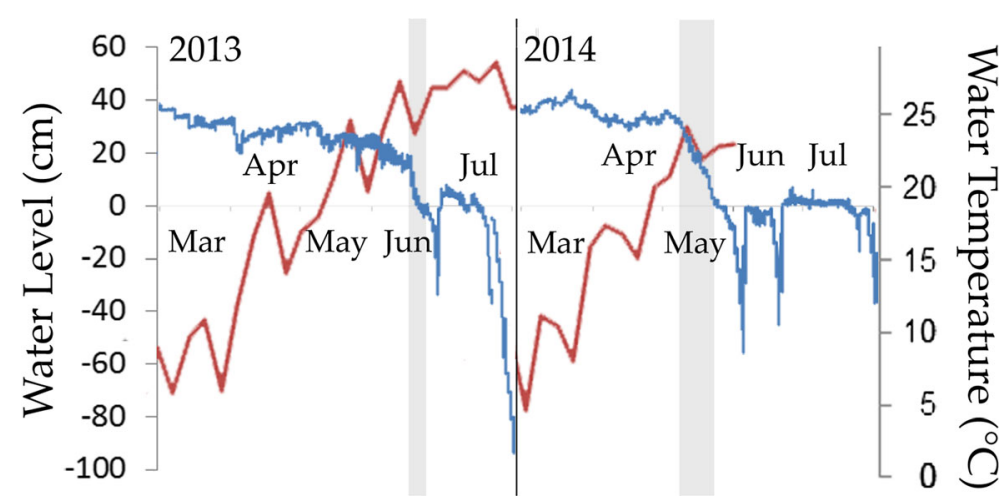

rather than to capture a particular phase of drawdowns, which were not under our control. We measured nitrate/ nitrite $\left(\mathrm{NO}_{x}\right)$ and ammonia/ammonium $\left(\mathrm{NH}_{x}\right)$ using a Lachat Quickchem 8000 autoanalyzer and total Phosphorus using the persulfate digestion-molybdate blue method (Wetzel and Likens 2000). We measured total $\mathrm{N}$ using a total nitrogen measuring unit (Shimadzu) in 2014 only (this instrument was not available in 2013). We found total $\mathrm{N}$ to be strongly correlated $\left(r^{2}=0.87\right)$ with $\mathrm{NH}_{x}$ in surface water during spring of 2014. We assume that a similar relationship between $\mathrm{NH}_{x}$ and total $\mathrm{N}$ existed in 2013 and we use a simple linear model to estimate total $\mathrm{N}$ from measured $\mathrm{NH}_{x}$ surface water data in 2013 (Fig. S2). Mean residual error from the model was less than $10 \%$.

We collected impoundment soil samples using a 2$\mathrm{cm}$ diameter punch tube in May and July 2013 and monthly from March to June 2014. In the field, we composited and homogenized soils from the $0-5$ - to $10-15-\mathrm{cm}$ depth intervals of three random replicates collected from each of 16 field plots. In the lab, we weighed, oven-dried, and re-weighed subsamples to estimate wet/dry ratios. We analyzed subsamples for total carbon and total $\mathrm{N}$ using a CE Instruments Flash Elemental Analyzer, and for total P using the molybdate blue method (Wetzel and Likens 2000) following nitricperchloric digestion.

\subsection{Nitrogen Source Estimation}

We consider four sources of $\mathrm{N}$ to Lake Mattamuskeet in our nutrient budget: (1) seasonal impoundment drawdown, (2) bird feces transported to the lake, (3) runoff/ leaching from cultivated areas of the lake's watershed, and (4) atmospheric deposition.

\subsubsection{Impoundments}

We estimated the mass of $\mathrm{N}$ inputs to Lake Mattamuskeet from springtime impoundment drawdown by multiplying impoundment water volume by total $\mathrm{N}$ concentration of surface water. We measured MI10N water level hourly using an automated capacitance level logger (Odyssey Data Flow Systems, Christchurch, New Zealand) and multiplied water depth at start of drawdown by impoundment area to calculate water volume. We used the mean surface water concentration from the measurement date closest to the timing of drawdown for our loading calculation. These key sampling dates were 9 June 2013, 3 days before drawdown, and 31 May 2014, roughly 8 days after drawdown. We followed the same protocol to estimate P inputs. The timing of sampling was constrained by the need for favorable weather for measurement of trace gas emission (low wind). Furthermore, we did not have prior knowledge of the exact timing of prescribed drawdowns.

To estimate impoundment contributions to the Lake Mattamuskeet nutrient budget, we extrapolated our observations at MI10N to all impoundment areas in the watershed. We include in this calculation 1001 ha of private impoundments on agricultural land, which attract overwintering waterfowl, but generally drain their fields in late February after the end of hunting season. Despite the management differences between the refuge impoundment where we took our measurements and these agricultural lands, we included all such areas in our estimate of "impoundment" contributions for the Lake $\mathrm{N}$ budget because of a lack of any data from agricultural impoundments. We report high and low impoundment $\mathrm{N}$ loads to Lake Mattamuskeet as the greater value and lesser value, respectively, from 2013 
to 2014. The mean we report is the arithmetic mean of these two values.

\subsubsection{Bird Transport}

The capacity for waterfowl to serve as nutrient vectors has been studied across a variety of aquatic habitats (Chaichana et al. 2010; Manny et al. 1994; Olson et al. 2005; Post et al. 1998). Waterfowl at Lake Mattamuskeet, particularly Snow Goose (Chen caerulescens) and Tundra Swan (Cygnus columbianus), feed in adjacent wetland or agricultural habitats, but return to the Lake to roost where their defecation represents an allochthonous source of N. While we lack highresolution quantitative data on the movement of all species of waterfowl, we observed a consistent daily influx of geese, Tundra Swan, and ducks into the lake and impoundments at dusk. To estimate the amount of $\mathrm{N}$ imported to Lake Mattamuskeet directly by bird movements, we follow the logic of Hahn et al. (2007) defecation model for quantification of allochthonous nutrient input into freshwater bodies by herbivorous waterbirds.

We estimated bird populations on the lake by using the mean counts of four aerial censuses collected by the US Fish and Wildlife Service in winter months during the study period (Table S1). We assume these populations are present at the lake for a season of 105 days (mid-November to mid-March) (Baldassarre et al. 2006), use Manny et al. (1994) defecation rate for Canada Goose (33 g goose ${ }^{-1}$ day $^{-1}$ ) and assume that this rate scales allometrically across species by body mass (Nagy et al. 1999). We use the following body masses: Tundra Swan, $6.75 \mathrm{~kg}$ (Limpert and Earnst 1994); Atlantic Canada Goose, $4.6 \mathrm{~kg}$ (Mowbray et al. 2002); Snow Goose, 2.6 kg (Mowbray et al. 2000); and Mallard mass for ducks, $1.2 \mathrm{~kg}$ (Drilling et al. 2002). We assume waterfowl feces have an $\mathrm{N}$ content of $45 \mathrm{mg} \mathrm{g}^{-1}$ based on a data synthesis (Hahn et al. 2007).

We multiplied our estimate of fecal mass produced by feces $\mathrm{N}$ content and report a range of estimates for waterfowl inputs to Lake Mattamuskeet. Our maximum value assumes that $60 \%$ of all bird excreta ends up in the lake, with the rest remaining in adjacent foraging areas, as Post et al. (1998) found in a study of Snow Geese. Imported feces fractions of 12 to $26 \%$ reported by Hahn et al. (2007) are probably more reasonable for our estimation of a mixed species assemblage and we use these values as for our minimum and mean, respectively.

\subsubsection{Agricultural Leaching/Runoff}

$\mathrm{N}$ export from fertilized agricultural lands in North Carolina's coastal plain varies widely based on how well-drained soils are and whether or not drainage is controlled with flash-board risers (Deal et al. 1986; Gilliam et al. 1978; Skaggs et al. 1980). Well-drained croplands have the potential to export large quantities of $\mathrm{NO}_{x}-\mathrm{N}$ because they lack the subsurface anoxia to support denitrification. Poorly drained agricultural soils, conversely, experience prolonged saturation, facilitating denitrification and exhibit much lower export of $\mathrm{NO}_{x}-\mathrm{N}$ and total N. Drainage control simply reduces the volume of outflowing water thus reducing total $\mathrm{N}$ flux.

As a result of variable drainage, among other factors, empirical $\mathrm{N}$ export data from cropland on North Carolina's Albemarle Peninsula range from 6.8 to $47.2 \mathrm{~kg} \mathrm{~N} \mathrm{ha}^{-1}$ year $^{-1}$ (Gilliam et al. 1978; Skaggs et al. 1980). The low-end measurements come from low-lying poorly draining deep peat soils, but even the highest estimate is from Portsmouth soil, which is classified as "poorly drained" (Soil Survey Staff 2015). Cultivated soils surrounding Lake Mattamuskeet represent a mosaic of soil series, but like Portsmouth, are poorly drained silty or sandy loams (Soil Survey Staff 2015). For our estimations of agricultural inputs to Lake Mattamuskeet, we use: (1) Skaggs et al. (1980) 3-year average for Albemarle Peninsula mineral and shallow organic soils of $15.6 \mathrm{~kg} \mathrm{~N} \mathrm{ha}^{-1}$ year $^{-1}$ as a low estimate; (2) Gilliam et al. (1978) average from three Albemarle Peninsula cultivated Portsmouth soils of $30.8 \mathrm{~kg}$ $\mathrm{N} \mathrm{ha}^{-1}$ year $^{-1}$ as a high estimate; and (3) the arithmetic mean of the previous two values as a mean estimate. To calculate the range of total loads into Lake Mattamuskeet, we multiplied each value by the area of agricultural land in the watershed.

\subsubsection{Atmospheric Deposition}

Local rates of wet deposition of $\mathrm{N}$ are reported from three National Atmospheric Deposition Network approved collectors at Pocosin Lakes National Wildlife Refuge (Ward 2009) and a private restored wetland (Ardón et al. 2010) approximately $25 \mathrm{~km}$ to the northwest and $40 \mathrm{~km}$ to north of Lake Mattamuskeet, respectively. Each study reports 
2 years of locally measured annual averages for a total of 8 data points. For reference, we compared these local data with estimates for Lake Mattamuskeet in 2012 (the most recent year of available data) using a hybrid method that incorporates both wet and dry deposition (Schwede and Lear 2014). We found that the mean of local measurements (5.1 kg N ha ${ }^{-1}$ year $^{-1}$ ) was remarkably similar to modeled estimates for Lake Mattamuskeet $\left(5.2 \mathrm{~kg} \mathrm{~N} \mathrm{ha}{ }^{-1}\right.$ year $^{-1}$ ) and that dry deposition contributes insignificantly to total $\mathrm{N}$ deposition. Therefore, we report the mean, minimum, and maximum of these locally reported wet deposition rates, as they likely represent the range of possible deposition rates for Lake Mattamuskeet.

\subsection{Nitrous Oxide Emission}

We measured emissions of the nitrificationdenitrification byproduct, nitrous oxide $\left(\mathrm{N}_{2} \mathrm{O}\right)$ (Firestone 1982), using a static chamber method in 16 plots monthly from March to June 2014. We built chambers from $1-\mathrm{m}$ sections of $55 \mathrm{~cm}$ diameter transparent TEDLAR plastic sleeves with circular Plexiglas caps fringed with closed-cell foam to make an air-tight seal. We affixed each cap with a 2-m sampling tube (1 $\mathrm{mm}$ inner diameter), a wide-bore closeable exhaust vent and a thermocouple for measuring internal chamber temperature. To set up the static chamber apparatus for $\mathrm{N}_{2} \mathrm{O}$ sampling, we attached the cap to the sleeve using binder clips, inserted a plastic brace into the base of the sleeve to maintain a cylindrical chamber headspace, and carried it into the wetland hanging from a $2-\mathrm{m}$ PVC pole. With the exhaust vent open, we lowered the chamber to rest on the rebar base using the PVC pole. As the chamber "skirt" submerged, air displaced by standing water was able to escape via the exhaust vent. We closed the vent before extracting the first headspace sample. We conducted chamber set up and sampling from a submerged cinder block platform to avoid disturbing sediments and driving ebullition into the chamber. Before extracting each sample, we flushed the sampling tube to mix this small volume (approximately $3 \mathrm{~mL}$ ) with the larger headspace (approximately $160 \mathrm{~L}$ ). We extracted one $60 \mathrm{~mL}$ headspace sample immediately following chamber set up and four additional samples at 5- to 8-min intervals for a total of five samples over an incubation of approximately $30 \mathrm{~min}$. We recorded internal chamber temperature immediately following each extracted sample. We measured chamber height above water level to calculate cylindrical chamber volume. During sampling dates with low or no surface water (May and June 2014), use of the chamber described above was not possible because standing water is necessary to create a sealed headspace. Instead, we used a permanent collar static chamber method, with a water-filled gutter and remote rod sampling system (described in detail in Winton and Richardson 2015).

We stored gas samples collected at the field site in labeled Mylar bags for transport back to the Duke University Wetland Center laboratory. We analyzed samples for $\mathrm{N}_{2} \mathrm{O}$ within one week of collection using a Varian 450 gas chromatograph equipped with an electron capture detector. We ran all samples in duplicate with the mean value used for gas flux calculations unless duplicate values differed by $>10 \%$, in which case the obviously outlying value was assumed to stem from analytical error and discarded. Flux was estimated by linear regression of sample concentration as a function of time elapsed. If a threshold $r$-squared value of 0.90 was not met, we removed 1 or 2 outlying points if it improved fit to $>0.90$ ( $15 \%$ of incubations), otherwise such estimates were treated as failed incubations and excluded from subsequent analysis (3\% of incubations). We estimated the minimum detectable flux to be $0.013 \mathrm{mg} \mathrm{N}_{2} \mathrm{O} \mathrm{m}{ }^{-2} \mathrm{~h}^{-1}$.

\subsection{Early Drawdown Simulation}

We postulated that an earlier season impoundment drawdown may reduce the amount of $\mathrm{N}$ going into Lake Mattamuskeet due to lower $\mathrm{N}$ content of impoundment surface water. Therefore we estimated a theoretical $\mathrm{N}$ export if drawdown were to have been completed on 1 May of 2013 and 2014, based on water level on that date and on total $\mathrm{N}$ concentrations, as measured on 9 May 2013 and 22 April 2014. Otherwise, we follow the same mass loading logic as described previously under 'Impoundments.'

\section{Results}

Spring drawdown of MI10N exported large amounts of $\mathrm{N}$ (14 and $22 \mathrm{~kg} \mathrm{~N} \mathrm{ha}^{-1}$ in 2013 and 2014, respectively) 
Table 1 Comparison of wetland size, drawdown volume, predrawdown surface water nutrients, nutrient export, and predrawdown peak bird use across 2 years at Mattamuskeet National
Wildlife Refuge in North Carolina, USA, and 1 year at Backus Lake in Michigan, USA (Kadlec 1962)

\begin{tabular}{|c|c|c|c|c|c|c|c|c|c|c|c|}
\hline \multicolumn{2}{|l|}{ Wetland } & \multicolumn{2}{|c|}{ Drawdown } & \multicolumn{2}{|c|}{ Surface water } & \multicolumn{4}{|c|}{ Nutrient export } & \multicolumn{2}{|c|}{ Peak birds } \\
\hline \multirow[t]{2}{*}{ Name } & \multirow[t]{2}{*}{ Size (ha) } & \multirow[t]{2}{*}{$\mathrm{cm}$} & \multirow[t]{2}{*}{$\mathrm{m}^{3}$} & \multirow{2}{*}{$\begin{array}{l}\text { Total P } \\
(\mathrm{mg} / \mathrm{L})\end{array}$} & \multirow{2}{*}{$\begin{array}{l}\text { Total N } \\
(\mathrm{mg} / \mathrm{L})\end{array}$} & \multicolumn{2}{|c|}{ Total P } & \multicolumn{2}{|c|}{ Total N } & \multirow{2}{*}{$\begin{array}{l}\text { Swans } \\
\text { (count) }\end{array}$} & \multirow{2}{*}{$\begin{array}{l}\text { Ducks } \\
\text { (count) }\end{array}$} \\
\hline & & & & & & $\mathrm{kg}$ & $\mathrm{kg} / \mathrm{ha}$ & $\mathrm{kg}$ & $\mathrm{kg} / \mathrm{ha}$ & & \\
\hline MI10N-2013 & 88 & 16 & 140,800 & 0.029 & $8.79^{\mathrm{a}}$ & 4 & 0.05 & 1238 & 14 & 5036 & 5484 \\
\hline MI10N-2014 & 88 & 34 & 299,200 & 0.121 & 6.49 & 36 & 0.41 & 1941 & 22 & 6450 & 25,529 \\
\hline $\begin{array}{l}\text { Backus Lake } \\
\quad \text { (Kadlec 1962) }\end{array}$ & 142 & 55 & 781,000 & 0.023 & 0.05 & 18 & 0.13 & 39 & 0.3 & 0 & 200 \\
\hline
\end{tabular}

Nutrient values are arithmetic means $(n=4)$

${ }^{\text {a }}$ Estimated from $\mathrm{NH}_{4}$ data. See Table $\mathrm{S} 2$

but little $\mathrm{P}\left(<0.5 \mathrm{~kg}\right.$ of $\mathrm{P} \mathrm{ha}^{-1}$ both years) (Table 1$)$. Nloading rates from impoundment drawdown are similar to published annual $\mathrm{N}$ exports from Albemarle Peninsula agricultural fields, which range from 16 to $31 \mathrm{~kg} \mathrm{~N} \mathrm{ha}^{-1}$ depending on soil drainage (Gilliam et al. 1978; Skaggs et al. 1980).

Although the magnitude of impoundment and agricultural field $\mathrm{N}$ sources is similar, the form of $\mathrm{N}$ is different. Agricultural runoff is typically high in $\mathrm{NO}_{x}$ (Skaggs et al. 1980), but MI10N surface waters had low concentrations of $\mathrm{NO}_{x}\left(<0.06 \mathrm{mg} \mathrm{L}^{-1}\right.$ until after drawdown) and were instead dominated by high concentrations of $\mathrm{NH}_{x}$ and organic $\mathrm{N}$ (Fig. 2).

Spring season total $\mathrm{N}, \mathrm{NH}_{x}$, and total $\mathrm{P}$ in $\mathrm{MI} 10 \mathrm{~N}$ surface water consistently showed a hump-shaped pattern, with the highest mean concentrations detected on 6 June 2013 and 31 May 2014, which roughly coincided with the drawdown target date on 1 June (Fig. 2). N dominated surface water with peak total N/P ratios of 303 and 53 (by mass) in 2013 and 2014, respectively (Table 1). Coupled nitrification-denitrification, as indicated by $\mathrm{N}_{2} \mathrm{O}$ emissions, was essentially undetectable in 2014 until after drawdown-oxidized sediment surfaces (Fig. 3). Simulations revealed that drawdown on 1 May could have reduced $\mathrm{N}$ export by more than $70 \%$ in both years (Table 2).

Agricultural runoff is the largest source of $\mathrm{N}$ to Lake Mattamuskeet (Table 2; Table S2). Wet deposition and impoundment drawdown contribute roughly one third and one fifth of total $\mathrm{N}$ inputs, respectively. Fecal inputs (bird transport) are relatively minor $(<2 \%)$ compared with these other sources despite the massive local population of overwintering waterfowl.

\section{Discussion}

\subsection{Nitrogen vs Phosphorus}

Because $\mathrm{N}$ is far more soluble than $\mathrm{P}$, which is typically bound to sediments, it is not surprising that our analysis of nutrients exported by impoundment drawdown showed high N/P ratios of 50 and 300 in 2013 and 2014, respectively. Impoundment surface soils contained $370 \mathrm{mg} \mathrm{P} \mathrm{kg}^{-1}$, which is at the upper end of "medium" for rice systems (International Rice Research Institute 1985) and have N/P ratios (Table S3) which are similar to those of other mineral soil wetlands on the North Carolina coastal plain (Richardson et al. 1988). It is possible that significant amounts of suspended sediments are also exported with impoundment surface water, which could occur via resuspension from wind, bioturbation, or the pumping process. Because high winds interfered with our ability to sample trace gas emissions, we specifically targeted sampling effort on calm days, and thus our surface water sampling may be biased against times of high sediment resuspension. Given the possibility that we are greatly underestimating $\mathrm{P}$ export via suspended sediments, we focus further analysis and discussion on the export of soluble $\mathrm{N}$, which we feel is much better constrained and quantified.

\subsection{Drawdown Timing}

Although agricultural lands often export high loads of $\mathrm{NO}_{x}-\mathrm{N}$ because efficient drainage prevents the anoxic soil conditions necessary for removal via denitrification (Skaggs et al. 1980), in MI10N most inorganic N was 
Fig. 2 Tukey boxplots comparing surface water ammonia/ammonium $\left(\mathrm{NH}_{x}\right)$, total nitrogen $(T N)$, nitrate/nitrite $\left(N O_{x}\right)$, and total phosphorus $(P)$ concentrations during the first half of two growing seasons at Marsh Impoundment 10 North at Mattamuskeet National Wildlife Refuge in North Carolina, USA. Whiskers include points within 1.5 times the interquartile range; outliers are individual points. Letters indicate results of Tukey's test of honest significant differences at $\alpha=0.05$. Differences in spring nutrient concentrations were not statistically significant in all cases, as tested by ANOVA and Tukey's honest significant differences test, but some true differences are likely obscured by low statistical power due to small sample sizes $(n=4)$. There were no significant differences among $\mathrm{NO}_{3}$ data. TN data for 2013 is modeled from $\mathrm{NH}_{x}$ (see "Methods")
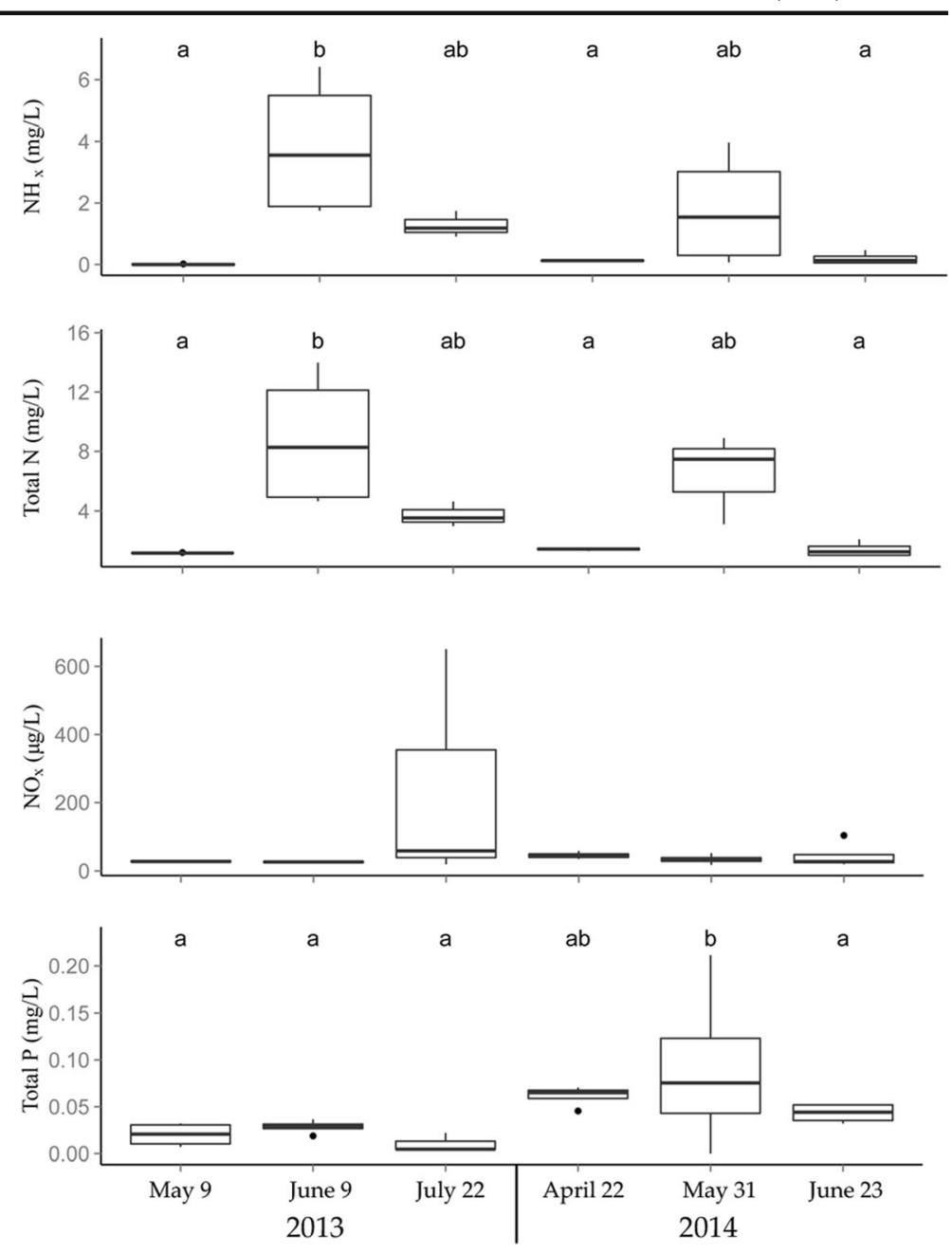

exported in the form of $\mathrm{NH}_{x}$, indicating a low capacity for nitrification. Low $\mathrm{NO}_{x}$ concentrations (Fig. 2) and undetectable $\mathrm{N}_{2} \mathrm{O}$ emissions prior to drawdown (Fig. 3), further indicate low nitrification and that $\mathrm{N}$ removal via denitrification was limited by low $\mathrm{NO}_{3}$. Thus, strategies to mitigate $\mathrm{N}$ loading from impoundments are antithetical to those for agricultural fields, which typically involve controlled drainage and use of buffering wetlands designed to provide an anoxic setting for denitrification (Cooper et al. 1987; Gilliam et al. 1979). For MI10N the problem is that soil remains wet for too long with organic and mineralizing $\mathrm{N}$ accumulating in surface waters. An earlier seasonal drawdown (Table 2) would create an oxidized soil surface and hyporheic zone, providing the potential for enhanced nitrification to complete the $\mathrm{N}$ cycle and stimulation of $\mathrm{N}$ removal during several months of moist-soil conditions prior to re-flooding in fall.
An earlier drawdown would also have the potential to reduce $\mathrm{N}$ export because impoundment $\mathrm{N}$ concentrations would be lower. The observed drawdown timing appears to coincide with maximum surface water $\mathrm{N}$ concentrations, and thus maximum potential $\mathrm{N}$ export (Fig. 2). The hump-shaped pattern of surface water nutrients we observed in spring is likely the result of increased $\mathrm{N}$ mineralization relative to assimilation as wetland sediments warmed, followed by coupled nitrification-denitrification once surface sediments become oxidized by the drawdown (as indicated by the pattern of $\mathrm{N}_{2} \mathrm{O}$ emissions; Fig. 3). These data suggest that if MI10N were drained earlier, before the acceleration of decomposition and $\mathrm{N}$ mineralization brought on by seasonal warming, it would load far less $\mathrm{N}$.

Our early drawdown simulation suggests that a drawdown on 1 May could achieve more than $70 \%$ reductions in $\mathrm{N}$ export based on the avoided export of 


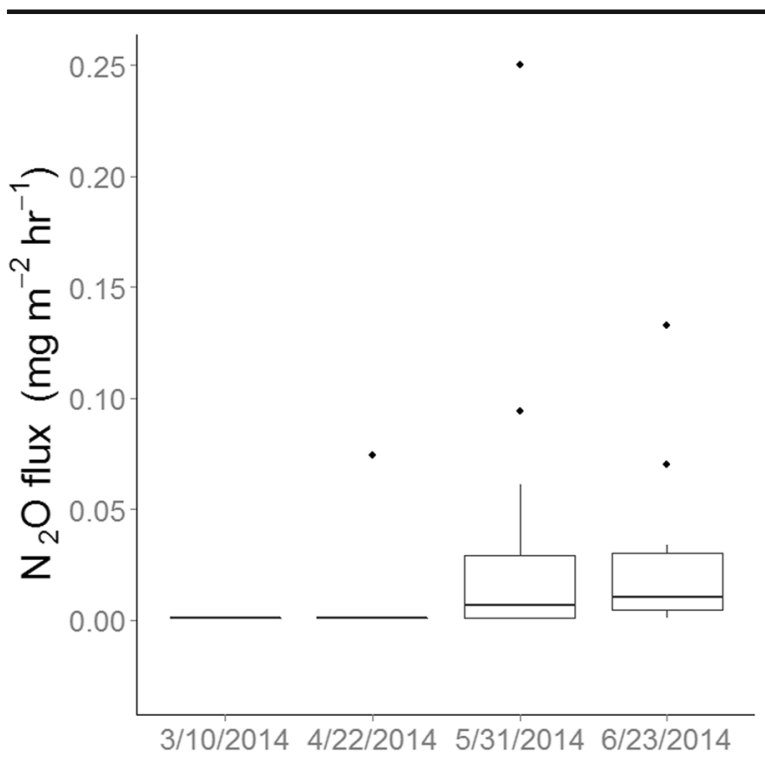

Fig. 3 Tukey boxplots of nitrous oxide $\left(\mathrm{N}_{2} \mathrm{O}\right)$ emissions from Marsh Impoundment 10 North at Mattamuskeet National Wildlife Refuge in North Carolina, USA. Whiskers include points within 1.5 times the interquartile range; outliers are individual points. $\mathrm{N}_{2} \mathrm{O}$ emissions were almost entirely less than the minimum detectable threshold of $0.013 \mathrm{mg} \mathrm{N}_{2} \mathrm{O} \mathrm{m}^{-2} \mathrm{~h}^{-1}$ until after spring drawdown oxidized surface soils around 23 May 2014

mineralized, concentrated $\mathrm{NH}_{x}$. Early drawdown also has the potential to stimulate the permanent $\mathrm{N}$ removal process of denitrification, by increasing $\mathrm{NO}_{3}$ availability. We caution, however, that our simple approach does not account for other potential feedbacks between water depth and biogeochemical processes. For example, decomposition of organic matter and mineralization could accelerate as water levels recede because of enhanced sunlight infiltration warming sediments. Since it takes several days of pumping to complete drawdown, there is ample time for such processes and any feedbacks to occur. An early drawdown strategy designed to reduce
$\mathrm{N}$ export should be field-tested in a controlled experimental setting.

In addition to the potential for unforeseen feedbacks, early drawdown also poses other potential tradeoffs. For example, increased pumping cost is one likely drawback of earlier drawdown, though its severity will vary depending on idiosyncratic patterns of seasonal rainfall. Early drawdown in 2014 would have required a minor increase $(<10 \%)$ in water volume pumped, but in 2013 the volume necessary to pump would have nearly doubled-late drawdown in 2013 allowed evapotranspiration and passive drainage to do roughly half of the work. Another drawback of early drawdown may be enhanced emissions of the greenhouse gas, nitrous oxide, produced as a byproduct of incomplete denitrification. However, a full accounting of the radiative impacts of early drawdown would need to include carbon emissions from diesel fuel burned by pumps, as well as impoundment methane emission and carbon storage dynamics (beyond the scope of this investigation). It is also possible that during a drought denitrification would be limited by highly oxic conditions allowing $\mathrm{N}$ to accumulate in impoundment soil. Under such a scenario, an early drawdown would only delay $\mathrm{N}$ export until drawdown the following year but have a limited net impact over two years.

The drawdown of refuge impoundments, which is timed to optimize habitat quality in impoundments, appears to have an unintended consequence of maximizing $\mathrm{N}$ export to the lake from these units. Thus, some of the waterfowl resources gained within the 2485 ha of impoundments in the Lake Mattamuskeet watershed may be offset by losses in the waterfowl-carrying capacity of the lake because of $\mathrm{N}$-driven phytoplankton

Table 2 Observed and simulated total nitrogen (TN) export from Marsh Impoundment 10 North at Mattamuskeet National Wildlife Refuge in North Carolina, USA

\begin{tabular}{|c|c|c|c|c|c|c|c|c|}
\hline \multirow[t]{2}{*}{ Year } & \multirow[t]{2}{*}{ Scenario } & \multicolumn{3}{|c|}{ Drawdown } & \multirow[t]{2}{*}{$\mathrm{TN}(\mathrm{mg} / \mathrm{L})$} & \multicolumn{3}{|c|}{ Export } \\
\hline & & Date & $\mathrm{cm}$ & $\mathrm{m}^{3}$ & & $\mathrm{~kg}$ & $\mathrm{~kg} / \mathrm{ha}$ & $\%$ change \\
\hline 2014 & Observed & 23 May & 34 & 299,200 & 6.49 & 1941 & 22 & na \\
\hline 2013 & Observed & 20 June & 16 & 140,800 & 8.79 & 1238 & 14 & na \\
\hline 2014 & Simulated & 1 May & 37 & 325,600 & 1.4 & 456 & 5 & -76.5 \\
\hline 2013 & Simulated & 1 May & 31 & 272,800 & 1.2 & 327 & 4 & -73.6 \\
\hline
\end{tabular}

Percent change refers to difference between simulated and observed $\mathrm{N}$ export for a given year 
blooms and SAV loss exacerbated by impoundment drawdown. Therefore, current impoundment management prescriptions may have more mixed effects on landscape-level waterfowl resources than has been previously realized.

\subsection{Role of Waterfowl}

Despite our finding that waterfowl flocks transport relatively minor amounts of $\mathrm{N}$ directly to Lake Mattamuskeet, birds may still play an indirect role in downstream $\mathrm{N}$ loading via impoundment drawdown. Compared with the lake, waterfowl are at least one order of magnitude more dense in MI10N (Table S4) and, based on a herbivorous bird nutrient loading model (Hahn et al. 2007), they may contribute up to one third of the amount of $\mathrm{N}$ exported by drawdown. Roughly half of exported impoundment $\mathrm{N}$ could stem from atmospheric deposition, which can be locally high in the context of adjacent agricultural sources (Ward 2009). We did not quantify $\mathrm{N}$ fixation or ground water $\mathrm{N}$ sources, though the later could be important at MI10N because of adjacent fertilized agriculture lands; we observed higher mean $\mathrm{N}$ concentrations in pore water compared with surface water in 7 out of 9 months throughout the study, indicating a diffusive flow of $\mathrm{N}$ from soil to surface water.

In addition to the potential to import $\mathrm{N}$ from adjacent agricultural lands (Post et al. 1998), birds may also exacerbate the $\mathrm{N}$ exported via impoundment drawdown through biogeochemical effects of their grazing and consumption of wetland vegetation. Herbivorous birds contribute to the mineralization of autochthonous $\mathrm{N}$ via the digestion and excretion of consumed plants and prey, thus making $\mathrm{N}$ more soluble and mobile during drawdown. They may also decrease the capacity of the impoundments to transform and remove excess $\mathrm{N}$ via coupled nitrification-denitrification by grazing on emergent macrophytes and reducing the amount of oxygen transported into soils by plants. Therefore, we find it likely that MI10N would load less $\mathrm{N}$ if it lacked such high densities of waterfowl.

The case of Backus Lake (Kadlec 1962), in which an impoundment that lacked a large waterfowl population exported very small amounts of $\mathrm{N}$, further supports the idea that we should expect to find high $\mathrm{N}$ export in regions where waterfowl seasonally concentrate, as we have documented at Mattamuskeet. Similar effects may be occurring unrecognized in other important waterfowl wintering and migration areas along the Atlantic Coast as well as the Gulf Coast and the Mississippi Alluvial Valley. $\mathrm{N}$ export from hydrologic drawdown of 36,000 ha of managed freshwater moist-soil impoundments at the National Wildlife Refuges across the southeastern USA (Table S5) may represent a widespread and hitherto unrecognized contributor to aquatic eutrophication.

Fertilizer runoff from agricultural lands is correctly recognized as the primary driver of anthropogenic eutrophication of lakes in many settings (e.g., Bennett et al. 1999; Qin et al. 2007), but if we ignore potential $\mathrm{N}$ contributions from hydrologically managed wildlife habitats, particularly those with dense bird populations, we may be overlooking a potent tool for nutrient mitigation. Since impoundments typically have a single outflow used once annually for drawdown, they could be considered a pollution point source-one that our analysis suggests could be relatively easy to mitigate through existing management infrastructure.

Table 3 Comparison of the estimated relative importance of nitrogen sources to Lake Mattamuskeet in North Carolina, USA

\begin{tabular}{|c|c|c|c|c|c|c|c|c|}
\hline \multirow[t]{3}{*}{ Nitrogen source } & \multirow{2}{*}{\multicolumn{3}{|c|}{$\frac{\text { Loading rate }}{\mathrm{kg} \mathrm{N} \mathrm{ha}^{-1} \text { year }^{-1}}$}} & \multirow[t]{3}{*}{ Area factor (ha) } & \multicolumn{4}{|c|}{ Total load } \\
\hline & & & & & \multicolumn{3}{|c|}{ Mg N year ${ }^{-1}$} & \multirow[t]{2}{*}{$\%$} \\
\hline & Mean & Low & High & & Mean & Low & High & \\
\hline Agricultural runoff ( Gilliam et al. 1978; Skaggs et al. 1980) & 23.2 & 15.6 & 30.8 & 4461 & 103 & 70 & 137 & 44.2 \\
\hline Wet deposition (Ward 2009; Ardon et al. 2010) & 5.1 & 2.8 & 6.8 & 16192 & 80 & 45 & 110 & 35.3 \\
\hline Impoundment drawdown & 18.1 & 14.1 & 22.1 & 2485 & 45 & 35 & 55 & 19.2 \\
\hline Bird transport & 0.2 & 0.1 & 0.5 & 16192 & 3 & 2 & 8 & 1.3 \\
\hline
\end{tabular}

Reported percentage shares of total load are based on mean values. Area factors refer to: the watershed covered by agriculture or impoundments or in the case of wet deposition and bird transport, lake area 


\subsection{Implications for Lake Mattamuskeet}

Our data from MI10N indicate that Mattamuskeet National Wildlife Refuge moist-soil impoundments have the potential to be important exporters of $\mathrm{N}$ via seasonal hydrologic drawdown, comparable on a perarea basis with local fertilized agricultural lands. In most watersheds, impoundments represent a minor component of land cover and thus cannot contribute significantly to downstream loading even with a high export per hectare. At Lake Mattamuskeet, however, some 2500 ha of impoundments are packed into a 12,000-ha watershed. The large impoundment area combined with a high loading rate leads us to conclude that impoundments should not be ignored when considering an $\mathrm{N}$ budget Lake Mattamuskeet's.

We caution, however, that our extrapolation to the 1001 ha of privately owned impoundments on agricultural land is uncertain. These lands are managed for both agriculture and waterfowl, which makes them fundamentally different from moist-soil impoundments in a few crucial ways: (1) vegetation cover is corn or soybean rather than aquatic vegetation; (2) fertilizers are applied; and (3) timing of hydrologic drawdowns is typically months earlier in the season. As a result, the timing and mechanism of nutrient loading may be much different in private impoundments compared with moist-soil units under refuge management. Nevertheless, if we use agricultural runoff values (Gilliam et al. 1978; Skaggs et al. 1980) instead of moist-soil impoundment values for agricultural impoundments, our study suggests that the magnitude of $\mathrm{N}$ loading would change little (Table 3).

Our $\mathrm{N}$ budget indicates that agricultural fields are the most important source of anthropogenic $\mathrm{N}$ to Lake Mattamuskeet but that the contribution from impoundments is not insignificant. This finding may be useful for managers of the Lake, because mitigation of agricultural sources of pollution can be expensive (Butt and Brown 2000; Rabotyagov et al. 2010), whereas our analysis suggests that impoundment $\mathrm{N}$ loading could be significantly reduced by early drawdown - a relatively minor, low-cost alteration to current impoundment management.

\section{Conclusions}

Waterfowl impoundment drawdowns may represent an important, unrecognized source of $\mathrm{N}$ pollution. Dense waterfowl populations may contribute to impoundment drawdown $\mathrm{N}$ loading via two mechanisms: (1) direct transport of nutrients from adjacent habitats, including agriculture; (2) mobilization of organic $\mathrm{N}$ through the digestion and excretion of autochthonous plants and prey. Adjustment of drawdown timing to avoid periods of maximum surface water $\mathrm{N}$ concentration and/or to oxygenate surface sediments and stimulate nitrogen cycling could mitigate undesirable $\mathrm{N}$ loading caused by birds and the drawdown of impoundment habitats. Further investigations should aim to quantify $\mathrm{N}$ export from other hydrologically managed impoundments with large bird populations and explore the relationship between drawdown timing, denitrification, and $\mathrm{N}$ export.

Acknowledgments We thank J. Bills for helping instrument the field site; W. Willis for assisting with laboratory analyses; M. River, M. Ho, and R. Lauzon for providing help and companionship in the field; P. Campbell, A. Stewart, and J. Fringeli of the US Fish and Wildlife Service for generous hospitality and providing access to the field site; J. Parker for helping design and construct static chambers; and D. Prasodjo for providing visual basic programming expertise. This manuscript was improved by comments from E. Bernhardt and D. Richter. Funding was provided by the Carolina Bird Club, the Duke University Wetland Center endowment and the Duke University Graduate School. The findings and conclusions in this article are those of the authors and do not necessarily represent the views of the US Fish and Wildlife Service.

\section{References}

Ardón, M., Morse, J. L., Doyle, M. W., \& Bernhardt, E. S. (2010). The water quality consequences of restoring wetland hydrology to a large agricultural watershed in the Southeastern Coastal Plain. Ecosystems, 13(7), 1060-1078. doi:10.1007 /s10021-010-9374-X.

Baldassarre, G. A., Bolen, E. G., \& Saunders, A. (2006). Waterfowl ecology and management. Malabar: Krieger.

Bennett, E. M., Reed-Andersen, T., Houser, J. N., Gabriel, J. R., \& Carpenter, S. R. (1999). A phosphorus budget for the Lake Mendota watershed. Ecosystems, 2(1), 69-75. doi:10.1007 /s100219900059.

Borum, J. (1985). Development of epiphytic communities on eelgrass (Zostera marina) along a nutrient gradient in a Danish estuary. Marine Biology, 87, 211-218.

Brandvold, D. K., Popp, C. J., \& Brierley, J. A. (1976). Waterfowl refuge effect on water quality: II. Chemical and physical parameters. Water Pollution Control Federation, 48(4), 680-687.

Butt, A. J., \& Brown, B. L. (2000). The cost of nutrient reduction: a case study of Chesapeake Bay. Coastal Management, 28(2), 175-185. doi:10.1080/089207500263585.

Cambridge, M. L., \& McComb, A. J. (1984). The loss of seagrasses in Cockburn Sound, Western Australia. I. The 
time course and magnitude of seagrass decline in relation to industrial development. Aquatic Botany, 20(3-4), 229-243. doi:10.1016/0304-3770(84)90089-5.

Carpenter, D. E., \& Dubbs, L. (2012). Albemarle-Pamlico Ecosystem Assessment 2012. Columbia: Albemarle-Pamlico National Estuary Partnership.

Chaichana, R., Leah, R., \& Moss, B. (2010). Birds as eutrophicating agents: a nutrient budget for a small lake in a protected area. Hydrobiologia, 646(1), 111-121. doi:10.1007 /s10750-010-0166-2.

Cooper, J., Gilliam, J., Daniels, R., \& Robarge, W. (1987). Riparian areas as filters for agricultural sediment. Soil Science Society of America Journal, 51, 416- 420.

Copeland, B. J., Hodson, R. G., Riggs, S. R., \& Easley Jr, J. E. (1983). Ecology of the Albermarle Sound, North Carolina: an estuarine profile. Washington: US Fish and Wildlife Service.

Dahl, T. E. (2011). Status and trends of wetlands in the conterminous United States 2004 to 2009. Washington: Fish and Wildlife Service.

Davis, A. B., Davis, K., \& Sheck, A. (2016). Effects of conductivity, nitrogen, and phosphorus on Phytoplankton in Lake Mattamuskeet. In AAAS 2016 Annual Meeting. Washington, 11-15 February 2016.

Deal, S. C., Gilliam, J. W., Skaggs, R. W., \& Konyha, K. D. (1986). Prediction of nitrogen and phosphorus losses as related to agricultural drainage system design. Agriculture, Ecosystems \& Environment, 18(1), 37-51. doi:10.1016 /0167-8809(86)90173-8.

Downing, J. A., \& Mccauley, E. (1992). The nitrogen: phosphorus relationship in lakes. Limnology and Oceanography, 37(5), 936-945. doi:10.4319/lo.1992.37.5.0936.

Drilling, N., Titman, R., \& McKinney, F. (2002). Mallard (Anas platyrhynchos). In A. Poole (Ed.), The birds of North America online. Ithaca: Cornell Laboratory of Ornithology.

Firestone, M. K. (1982). Biological denitrification. In F. J. Stevenson (Ed.), Nitrogen in agricultural soils (pp. 289326). Madison: American Society of Agronomy, Inc.

Forrest, L. C. (1999). Lake Mattamuskeet. New Holland and Hyde County: Arcadia Publishing.

Fry, J. A., Xian, G., Jin, S., Dewitz, J. A., Homer, C. G., Limin, Y., et al. (2011). Completion of the 2006 national land cover database for the conterminous United States. Photogrammetric Engineering and Remote Sensing, 77(9), 858-864.

Gilliam, J., Skaggs, R., \& Weed, S. (1979). Drainage control to diminish nitrate loss from agricultural fields. Journal of Environmental Quality, 8(3), 137-142.

Gilliam, J. W., Skaggs, R. W., \& Weed, S. (1978). An evaluation of the potential for using drainage control to reduce nitrate loss from agricultural fields to surface waters. Raleigh: School of Agriculture and Life Sciences, North Carolina State University.

Gould, D., \& Fletcher, M. (1978). Gull droppings and their effects on water quality. Water Research, 12, 665-672.

Hahn, S., Bauer, S., \& Klaassen, M. (2007). Quantification of allochthonous nutrient input into freshwater bodies by herbivorous waterbirds. Freshwater Biology, 53, 181-193. doi:10.1111/j.1365-2427.2007.01881.x.

Healey, F., \& Hendzel, L. (1980). Physiological indicators of nutrient deficiency in lake phytoplankton. Canadian Journal of Fisheries and Aquatic Sciences, 37, 442-453.

Hearns, W. E. (1910). Soil Survey of the Lake Mattamuskeet Area, North Carolina. Washington: US Department of Agriculture.
Heck, K., Able, K., Roman, C., \& Fahay, M. (1995). Composition, abundance, biomass, and production of macrofauna in a New England estuary: comparisons among eelgrass meadows and other nursery habitats. Estuaries, 18(2), 379-389.

Hecky, R., \& Guildford, S. (1984). Primary productivity of Southern Indian Lake before, during, and after impoundment and Churchill River diversion. Canadian Journal of Fisheries and Aquatic Sciences, 41, 591-604.

International Rice Research Institute. (1985). Wetland soils: characterization, classification, and utilization. Los Baños: International Rice Research Institute.

Johnson, F. A., \& Montalbano, F., III. (1989). Southern reservoirs and lakes. In L. M. Smith, R. L. Pederson, \& R. M. Kaminski (Eds.), Habitat management for migrating and wintering waterfowl in North America (pp. 93-116). Lubbock: Texas Tech University Press.

Kadlec, J. (1962). Effects of a drawdown on a waterfowl impoundment. Ecology, 43(2), 267-281.

Kemp, W., Batiuk, R., Bartleson, R., Bergstrom, P., Carter, V., Gallegos, C. L., et al. (2004). Habitat requirements for submerged aquatic vegetation in Chesapeake Bay: water quality, light regime, and physical-chemical factors. Estuaries, 27(3), 363-377.

Kemp, W., Twilley, R., Stevenson, J. C., Boynton, W. R., \& Means, J. C. (1983). The decline of submerged vascular plants in upper Chesapeake Bay: summary of results concerning possible causes. Marine Technology Society Journal, 17(2), 78-89.

Kolzau, S., Wiedner, C., Rücker, J., Köhler, J., Köhler, A., \& Dolman, A. M. (2014). Seasonal patterns of nitrogen and phosphorus limitation in four German lakes and the predictability of limitation status from ambient nutrient concentrations. PloS One, 9(4), e96065. doi:10.1371/journal.pone.0096065.

Limpert, R. J., \& Earnst, S. L. (1994). Tundra Swan (Cygnus columbianus). In A. Poole (Ed.), The birds of North America online. Ithaca: Cornell Laboratory of Ornithology. doi:10.2173/bna.89.

Lubbers, L., Boynton, W., \& Kemp, W. (1990). Variations in structure of estuarine fish communities in relation to abundance of submersed vascular plants. Marine Ecology Progress Series, 65, 1-14.

Manny, B., Johnson, W., \& Wetzel, R. (1994). Nutrient additions by waterfowl to lakes and reservoirs: predicting their effects on productivity and water quality. Hydrobiologia, 279(280), 121-132.

McGlathery, K. (1995). Nutrient and grazing influences on a subtropical seagrass community. Marine Ecology Progress Series, 122, 239-252.

Mowbray, T. B., Cooke, F., \& Ganter, B. (2000). In A. Poole (Ed.), Snow goose (Chen caerulescens). The birds of North America online. Ithaca: Cornell Lab of Ornithology. doi:10.2173/bna.514.

Mowbray, T. B., Ely, C. R., Sedinger, J. S., \& Trost, R. E. (2002). Canada goose (Branta canadensis). In A. Poole (Ed.), The birds of North America online. Ithaca: Cornell Laboratory of Ornithology. doi:10.2173/bna.682.

Nagy, K. A., Girard, I. A., \& Brown, T. K. (1999). Energetics of free-ranging mammals, reptiles, and birds. Annual Review of Nutrition, 19, 247-277. doi:10.1146/annurev.nutr.19.1.247.

North American Waterfowl Management Plan Committee. (2012). North American waterfowl management plan 2012: people 
conserving waterfowl and wetlands. Washington: Fish and Wildlife Service.

North Carolina Department of Health Environment and Natural Resources. (2013). Lake \& Reservoir Assessments TarPamlico River Basin. Raleigh: North Carolina Division of Water Quality.

Olson, M. H., Hage, M. M., Binkley, M. D., \& Binder, J. R. (2005). Impact of migratory snow geese on nitrogen and phosphorus dynamics in a freshwater reservoir. Freshwater Biology, 50(5), 882-890. doi:10.1111/j.1365-2427.2005.01367.x.

Orth, R. J., \& Moore, K. A. (1983). Chesapeake Bay: an unprecedented decline in submerged aquatic vegetation. Science, 222, 51-53. doi:10.1126/science.222.4619.51.

Post, D. M., Taylor, J. P., Kitchell, J. F., Olson, M. H., Schindler, D. E., \& Herwig, B. R. (1998). The role of migratory waterfowl as nutrient vectors in a managed wetland. Conservation Biology, 12(4), 910-920. doi:10.1046/j.1523-1739.1998.97112.x.

Qin, B., Xu, P., Wu, Q., Luo, L., \& Zhang, Y. (2007). Environmental issues of Lake Taihu, China. Hydrobiologia, 581(1), 3-14. doi:10.1007/s10750-006-0521-5.

Rabotyagov, S., Campbell, T., Jha, M., Gassman, P., Arnold, J., Kurkalova, L., et al. (2010). Least-cost control of agricultural nutrient contributions to the Gulf of Mexico hypoxic zone. Ecological Applications, 20(6), 1542-1555.

Richardson, C. (1983). Pocosins: vanishing wastelands or valuable wetlands? Bioscience, 33(10), 626-633.

Richardson, C. J., Walbridge, M. R., \& Burns, A. (1988). Soil chemistry and phosphorus retention capacity of North Carolina coastal plain swamps receiving sewage effluent. Raleigh: North Carolina Water Resources Research Institute of the University of North Carolina.

Schwede, D. B., \& Lear, G. G. (2014). A novel hybrid approach for estimating total deposition in the United States. Atmospheric Environment, 92, 207-220.

Short, F. T., \& Wyllie-Echeverria, S. (1996). Natural and humaninduced disturbance of seagrasses. Environmental Conservation, 23(1), 17-27. doi:10.1017/S0376892900038212.

Skaggs, R. W., Gilliam, J. W., Sheets, T. J., \& Barnes, J. S. (1980). Effect of agricultural land development on drainage waters in the North Carolina Tidewater region. Raleigh: North Carolina Water Resources Research Institute of the University of North Carolina.
Smith, V. H. (2003). Eutrophication of freshwater and coastal marine ecosystems a global problem. Environmental Science and Pollution Research, 10(2), 126-139. doi:10.1065/espr2002.12.142.

Soil Survey Staff. (2015). Web soil survey. Natural Resources Conservation Service, United States Department of Agriculture. http://websoilsurvey.nrcs.usda.gov/

Strader, R., Stinson, P., \& Jackson, M. (2005). Moist-soil management guidelines for the US Fish and Wildlife Service Southeast Region. Migratory Bird Field Office, Division .... Jackson: US Fish and Wildlife Service.

Tomasko, D. a., Dawes, C. J., \& Hall, M. O. (1996). The effects of anthropogenic nutrient enrichment on turtle grass (Thalassia testudinum) in Sarasota Bay, Florida. Estuaries, 19(2B), 448-456. doi:10.2307/1352462.

U.S. Fish and Wildlife Service. (2015). Science to support hydrology and water quality management decision-making at Lake Mattamuskeet.

Walker, D., \& McComb, A. (1992). Seagrass degradation in Australian coastal waters. Marine Pollution Bulletin, 25(58), 191-195. doi:10.1016/0025-326X(92)90224-T.

Ward, S. (2009). Preliminary results of an ongoing investigation of ammonia emissions from a large-scale egg-laying operation near Pocosin Lakes National Wildlife Refuge. Raleigh: US Fish and Wildlife Service.

Waters, M. N., Piehler, M. F., Rodriguez, A. B., Smoak, J. M., \& Bianchi, T. S. (2009). Shallow lake trophic status linked to late Holocene climate and human impacts. Journal of Paleolimnology, 42(1), 51-64. doi:10.1007/s10933-0089247-x.

Waters, M. N., Piehler, M. F., Smoak, J. M., \& Martens, C. S. (2010). The development and persistence of alternative ecosystem states in a large, shallow lake. Freshwater Biology, 55(6), 1249-1261. doi:10.1111/j.1365-2427.2009.02349.x.

Wetzel, R. G., \& Likens, G. E. (2000). Limnological analyses (3rd ed.). New York: Springer.

Winton, R. S., \& Richardson, C. J. (2015). A cost-effective method for reducing soil disturbance-induced errors in static chamber measurement of wetland methane emissions. Wetlands Ecology and Management. doi:10.1007/s11273015-9468-5 